\title{
Minimally Invasive Total Hip Arthroplasty
}

\author{
Mel S. Lee \\ College of Medicine, Chang Gung University, \\ Department of Orthopedic Surgery, Chang Gung Memorial Hospital at Linkou \\ Taiwan
}

\section{Introduction}

Total hip arthroplasty (THA) is one of the most reliable procedures that can provide shortterm high clinical success rates and long-term durable outcome. The surgery has been developed for more than 40 years and most of the clinical practices are standardized for the patient care. In the past, THA had been done by making a wound about $25 \mathrm{~cm}$ in length. Many surgeons believed that big wounds should be the standard approach for THA because the surgery is a big surgery and could only be reliably done with big wounds. In recent 10 years, this concept of "big surgery-big wound" has been challenged in many fields of surgery. Taking the arthroscopic ligament reconstruction surgery or laparoscopic cholecystectomy surgery as the examples, many surgical procedures can now be safely and adequately performed by the minimally invasive (MIS) approaches. Although impossibly be done by an arthroscopy, the surgical approaches for THA have been adopting the concept of MIS and modified by many surgeons. However, the definition of a MIS-THA is not as straightforward as the words meanings. Based on the incision length, it is generally agreed upon that an incision less than $10 \mathrm{~cm}$ can be defined as MIS-THA. However the MIS can also be interpreted as less soft tissue trauma or less bone tissue trauma when doing the THA. The incision wound length then is not necessarily equal to the extent of tissue injury during the procedure. To date, the MIS-THA can be divided into two categories. One decreases the wound and muscle cutting and emphasizes the tissue repair through either a lateral or a posterior route. [1-4] The other spares muscle sectioning during the procedure through one $[5,6]$, two [1,7-11], or multiple [12] incisions. The abridged incision methods minimize the incision length and can be extensile if difficulties are encountered during THA. The muscle sparing methods use tissue intervals for surgery but could be difficult if complications happened intraoperatively. In the literature, the complication rates are significantly higher in inexperienced, low-volume surgeons in the "learning curve" period for the muscle sparing techniques. [13] THA, however, is a reliable procedure and its clinical results should not be compromised by the surgical approaches. For those surgeons who start to learn the procedure, standard surgical approach with bigger wounds is strongly recommended.

In the learning curve period of the MIS-THA, the incision should start from a standard length and then gradually reduces its size as the experiences accumulated. To master the MIS-THA surgical techniques, surgeons also need to familiar with the anatomy and different surgical approaches for THA. [14] 


\section{Surgical approaches for total hip arthroplasty}

For the surgical approaches, THA can be done by different routes. Each approach has its potential advantages and limitations. Followings are the commonly used approaches for THA.

\subsection{The transtrochanteric approach}

The transtrochanteric approach osteotomizes the greater trochanter and retracts it along with the gluteal medius and minimus anteriorly to facilitate exposure. It is nowadays seldom performed on primary cases and is performed selectively on revision cases, secondary reconstruction after hip fractures, and for distal transfer of the greater trochanter. The transtrochanteric approach is originally done at the level between the insertion of hip abductors and the origin of the vastus lateralis. It is however associated with complications such as nonunion or proximal migration of the greater trochanter that often result in weakness of the abductors with marked limping gait or even instability of the THA. To avoid proximal migration of the greater trochanter and enhance the union rates, both the insertion of gluteal muscles and the origin of the vastus lateralis can be preserved on the greater trochanter as a whole construct and be slide anteriorly during the procedure. The trochanteric slide or flip approach prevents untoward proximal migration of the greater trochanter and enhances the fixation stability of the trochanter. [15] The trochanteric slide technique can be further modified by extending the osteotomy to the lateral cortex of the proximal femur to facilitate implant or cement removal in complex cases. [16]

\subsection{The transgluteal approach (direct lateral)}

The transgluteal approach splits the gluteal medius along its muscle fibers and cut about one third or half of the gluteal medius from its musculotendinous insertion on the trochanter. (Figure 1 ) The muscle is retracted ventrally and the underlying gluteal minimus

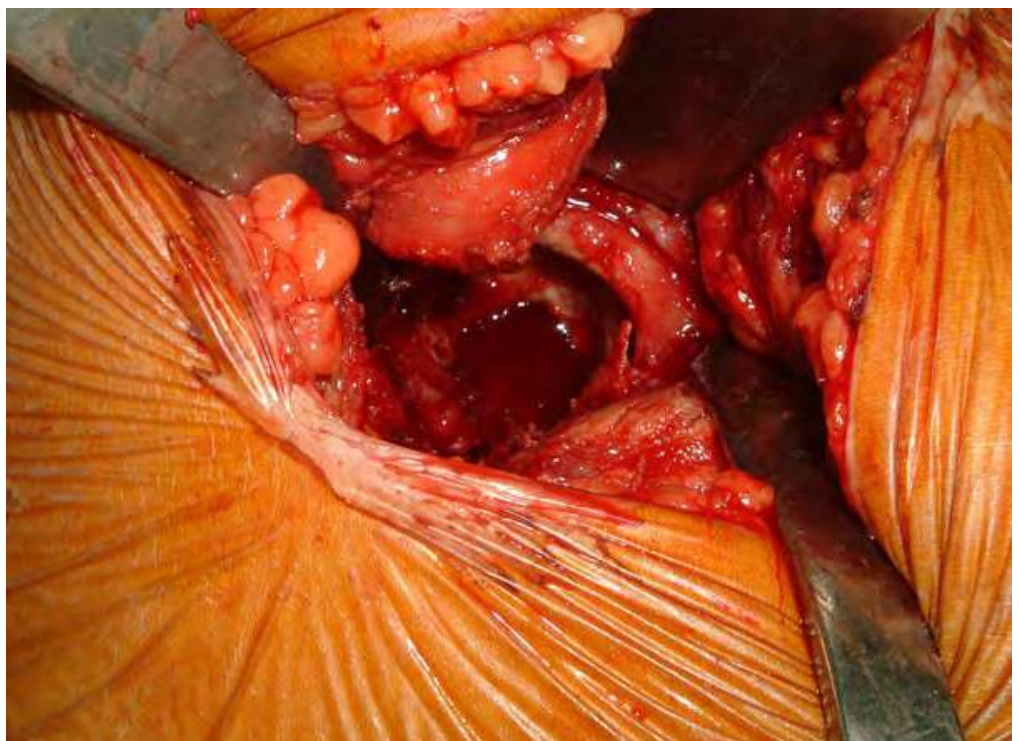

Fig. 1. The direct lateral approach detaches $1 / 3$ of the gluteal medius from the greater trochanter to facilitate anterior dislocation of the hip joint. 
and the joint capsule are then incised in a T-manner to facilitate anterior dislocation of the hip. In standard lateral approach of Hardinge [17], part of the vastus muscle can be incised to help the exposure. In modified method, the origins of the vastus muscle can be spared to decrease the tissue trauma. Possible risks of the approach involve an injury to the muscular braches of the superior gluteal nerve or direct injury to the muscle fibers by compression or retraction during surgery. This will result in damage to the gluteal muscles or muscular insufficiency and is associated with higher chance of Trendelenburg sign (Figure 2) postoperatively. [18]

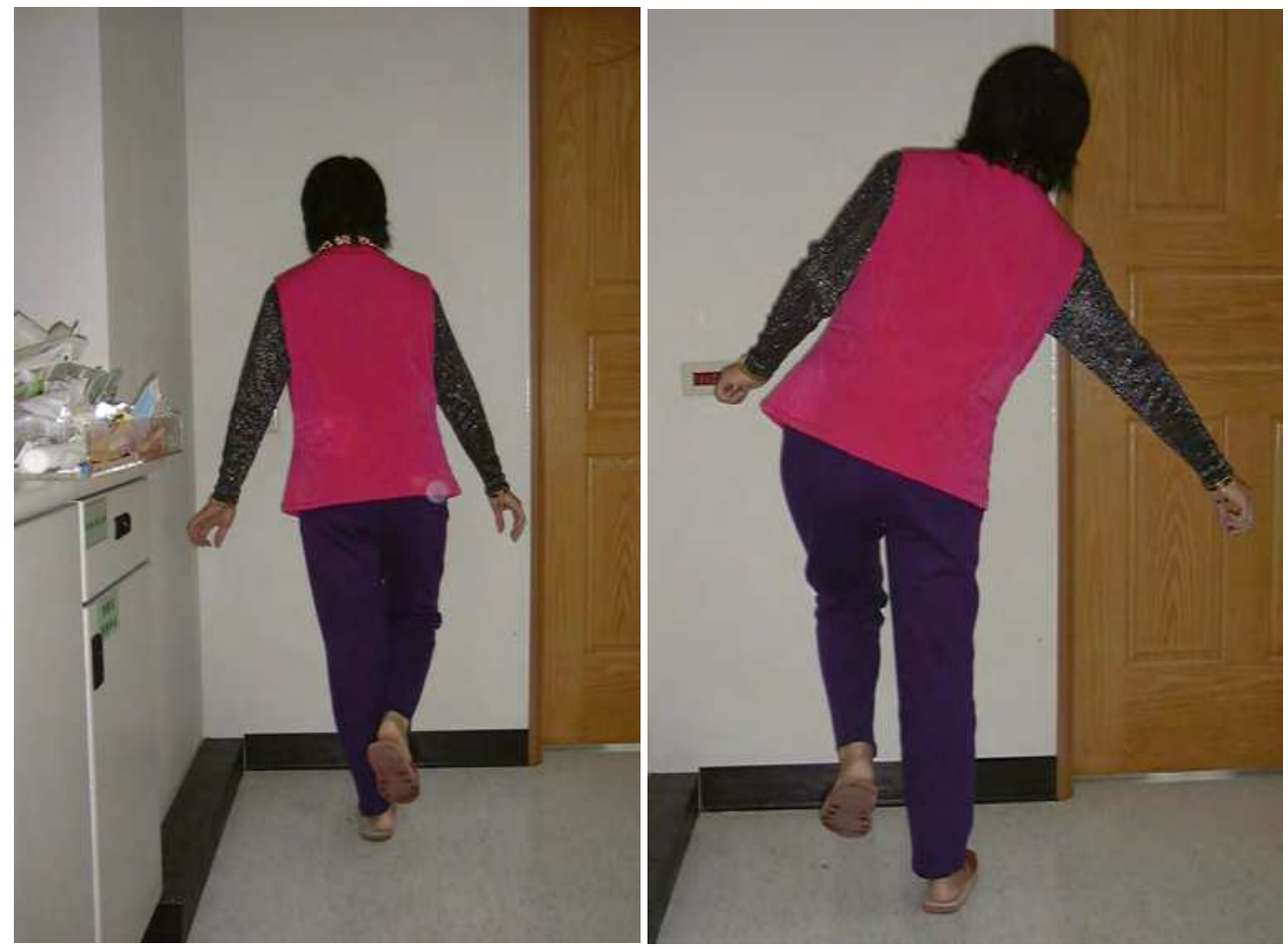

Fig. 2. The patient with abductors weakness. (A) When standing on the sound leg, the pelvis can be kept level and will not drop. (B) When standing on the affected leg, patient will compensatory list to the affected side to avoid pelvis dropping. (Duchenne sign)

\subsection{The posterolateral approach}

The posterolateral approach is probably the most popular surgical approach for THA for many orthopedic surgeons. Skin incision is made along the posterior border of the proximal femur centered on the top of the greater trochanter. The muscle part of the gluteal maximus is split along its fibers. The short external rotators and the posterior joint capsule are detached from the posterior border of the femur. The hip is dislocated posteriorly by internally rotation, flexion, and adduction. Cares should be taken to identify and protect the sciatic nerve during the procedure. After the THA, a secure and tight repair of the posterior capsule should be performed to decrease the dislocation rates. $[3,4]$ 


\subsection{The anterolateral approach}

Between the anatomical interval of the gluteal medius and tensor fascia latae superficially, the so-called Watson-Jones interval, the anterior hip joint capsule can be exposed by retracting the rectus femoris medially and the gluteal muscles laterally. During the exposure of the anterior femoral neck, the assistant can gradually rotate the leg in externally rotated position. Usually the neck should be cut in place because the complete anterior dislocation of the hip is difficult. The acetabulum is exposed by placing two retractors, one on the front to protect the rectus femoris and one on the back to push the femur posteriorly. The femur is exposed by placing the limb in hyperextension, adduction, and $90^{\circ}$ external rotation. One retractor is placed behind the greater trochanter to protect the gluteus medius. One retractor is placed below the proximal medial neck to leverage the proximal femur for canal preparation. [5] Because only the fasica layers were split without detaching muscles from the hip, special retractors are often needed to facilitate exposure and dislocation of the hip.

\subsection{The anterior approach}

The direct anterior approach is usually performed with the patient in the supine position. [6] Dissection is in the Smith-Peterson interval between the fascia of the Sartorius muscle and the fascia of the tensor fascia lata muscle. The skin incision begins from a point distal to the anterior superior iliac spine and extends obliquely in the direction of the tensor fascia lata. By blunt dissection, the Sartorius muscle can be retracted medially and the muscle belly of the fascia lata can be retracted laterally. At this point, the underlying fascia between the rectus femoris and the inferior fasica layer of the tensor fascia lata can be exposed. In this layer, the ascending branches of the lateral femoral circumflex vessels can be identified and ligated. A Cobra retractor is put around the anterior inferior femoral neck above the capsule to elevate the reflected head of rectus femoris. Another Hohmann retractor is put around the posterior femoral neck and the posterior acetabulum to retract the gluteal muscles behind. Sometimes part of the reflected head of the rectus femoris need to be released to help the exposure. The anterior hip capsule can then be incised or excised. The retractors can then be put intra-articularly while cutting the femoral neck. For the aceabular preparation, visualization of the bony landmarks can be done by putting a Hohmann retractor under the posterior rim of acetabulum to push the proximal femur posteriorly and by another retractor on the medial wall of the acetabulum above the pubic bone. For femoral preparation, the leg needs to be positioned in hyperextension, adduction and external rotation. The posterior medial capsule along with the short external rotator muscles are released in a stepwise manner. The leg is put in the "figure of 4" position and a blunt Cobra retractor can be put behind the greater trochanter to gradually elevate the proximal femur.

\subsection{The combined approach}

By combining the above surgical routes, THA can also be done by the double incision methods [1,7-11] or the triple incision method [12]. The double incision method is a modified method of the direct anterior approach by Berger and Mears. [14] Patient is put in the supine position and the hip joint is approached via the Smith-Peterson interval. $[7,8]$ The anterior skin incision is made along the long axis of the femoral neck. The fascia and muscle over the hip joint are split without cutting into their attachment. Two Hohmann retractors, one medial and one lateral to the femoral neck, are used to retract the gluteal medius laterally and the rectus femoris medially. The femoral neck needs to be cut in situ because dislocation of the hip joint is almost impossible by such a limited dissection. Usually the 
femoral neck needs to be doubly cut at the head-neck junction and at the standard neck cut level. After removing the bone block of the femoral neck, a space is created for the ease of femoral head retrieval. The acetabulum is prepared as the standard direct anterior approach. Another incision is made posterior to the greater trochanter. The fascia and muscles of the gluteal maximus are split in line with its muscle fibers. Similar to the technique of femoral intramedullary nailing, the femoral canal is prepared by sequential enlargement with reamers. Under the fluoroscopic guidance, both the acetabular and the femoral component can be implanted in predetermined position.

We and others have modified the two-incision technique by putting the patient in the lateral decubitus position [9-11]. The anterior skin incision is made perpendicular to the long axis of the femoral neck about 3 to 4 finger-breadth distal to the ilioinguinal line. (Figure 3 ) The hip joint is approached through the Smith-Peterson interval. Double neck cutting to the hip joint is also needed. While the anterior skin incision is made along the intertrochanteric line, the greater trochanter and the proximal femur can be visualized more easily by gentle retraction of the gluteus medius and tensor fascia lata. By this modification, the process of femoral canal preparation can be safely done under direct vision without the help of the fluoroscopic monitoring. [9-11,19]

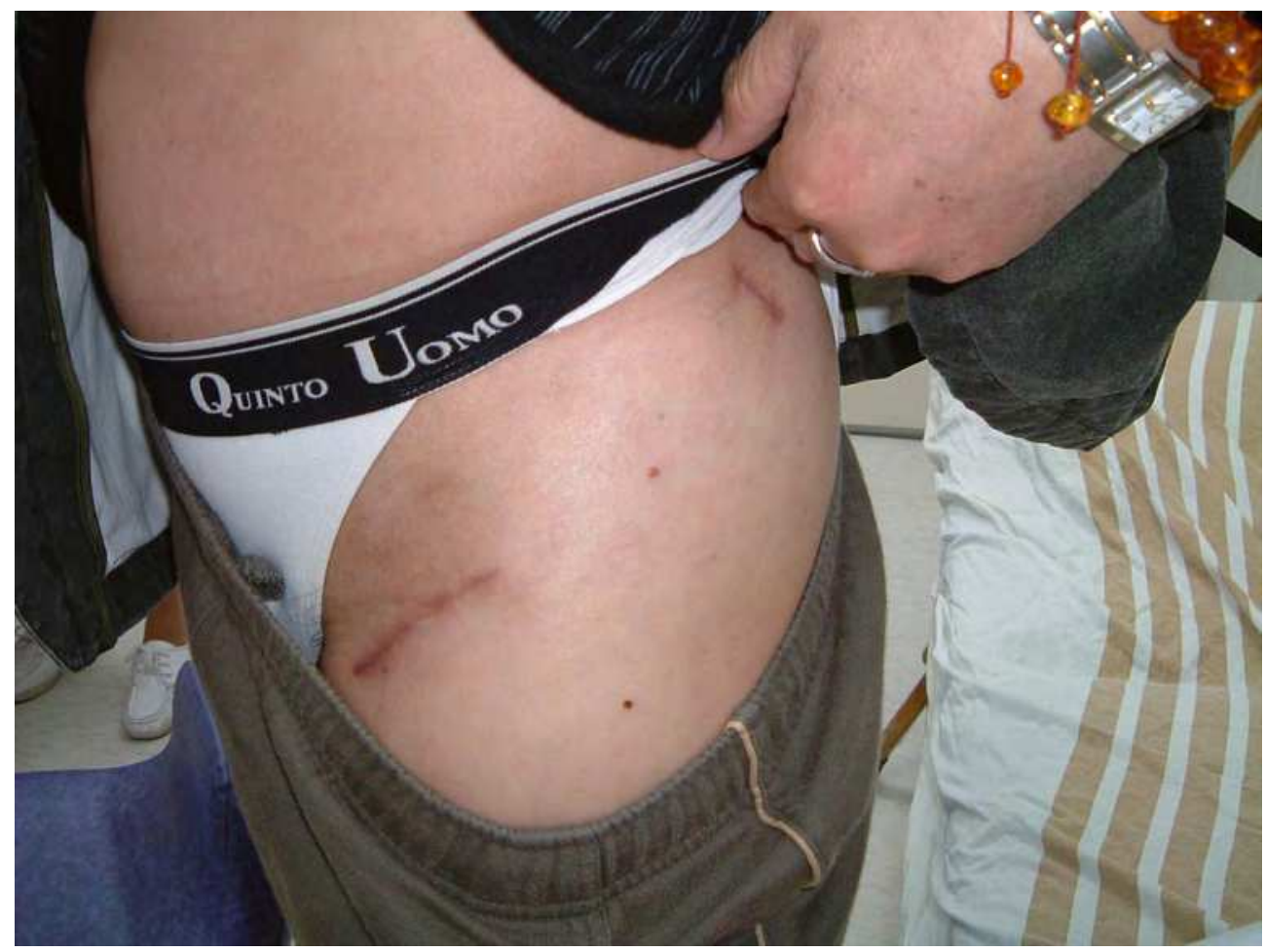

Fig. 3. Skin incision of the modified two-incision method.

The triple incision method is similar to the double incision method. It can be done with the patient in the supine or in the lateral decubitus position. Basically the incisions for the 
acetabulum and the femur exposure are not different from the original 2-incision method and the tissue intervals used for surgery are the same. The third incision is only needed in some heavy muscular or obese cases whereas the appropriate handling of the surgical instruments to the desirable position cannot be done. [12]

\subsection{The omega approach}

The approach is a lateral approach to the hip joint with the patient in the supine or lateral position. [20] Skin incision is centered over the greater trochanter. The fascia lata and gluteus maximus are split in the line of the skin incision. An aponeurotic flap including the gluteus medius and the vastus lateralis is elevated subperiosteally. The dissection starts proximally in the plane between the tendons of gluteus medius and piriformis. The attachments of gluteus medius and gluteus minimus from the greater trochanter are mobilized by sharp dissection. The dissection continues distally to involve the anterior border of the vastus lateralis as a single continuous strip of tissue. The shape of the incision resembles the Greek letter omega. Care should be taken to create the "osteoaponeurotic" flap as a whole construct. The entire muscle flap of gluteus medius, minimus, and vastus lateralis is mobilized off the anterior capsule of the hip. The hip capsule is incised in a Tshape manner. Subsequent repair of the osteoaponeurotic flap can be augmented by interrupted non-absorbable sutures by passing the sutures through holes drilled in the bone.

\subsection{Patient positioning and special operation table}

MIS-THA can be done with the patient in the supine or lateral position depending on the surgeon's preference. As a general rule, if the THA is performed from the anterior route, a supine position will be more intuitive. If the THA is performed from the lateral or posterolateral route, a lateral position should be easier for the surgeon. The patient positioning is important in performing the THA because the implant positions are often determined intraoperatively with the reference to the patient's position, bony anatomy, and the environmental setting. In MIS-THA, it is even more important because the bony anatomy and landmarks are sometimes less visualized. The proper patient positioning is also necessary during the THA because the operated leg needs to be manipulated in different directions and positions to facilitate hip dislocation, bone preparation, and check for the leg length equality.

In the supine position, a sandbag or an inflatable pillow can be put beneath the buttock to help the hyperextension of the hip. The foot-piece of the operative table on the operated side can be lowered and the leg can be put in a "figure of 4" position in hyperextension, adduction, and external rotation. The proximal femur then can be more easily accessed from the anterior wound. [21]

In the lateral position, the positions and directions of the operated leg depend on the surgical approaches for the femur preparation. With the posterolateral approach, the leg needs to be adducted, internally rotated, and flexed. With the transgluteal approach or omega approach, the leg needs to be adducted, externally rotated, and flexed. Both the posterolateral and the transgluteal approach can be done on a standard operation table. An operation table with the foot-piece that can be removed or lowered is required for the anterolateral (Watson-Jones) approach because during the femur preparation the leg needs to be adducted, externally rotated, and hyper-extended. (Figure 4) If the operation table is not available, the patient needs to be put toward the side of the table to facilitate the hip extension postion. 


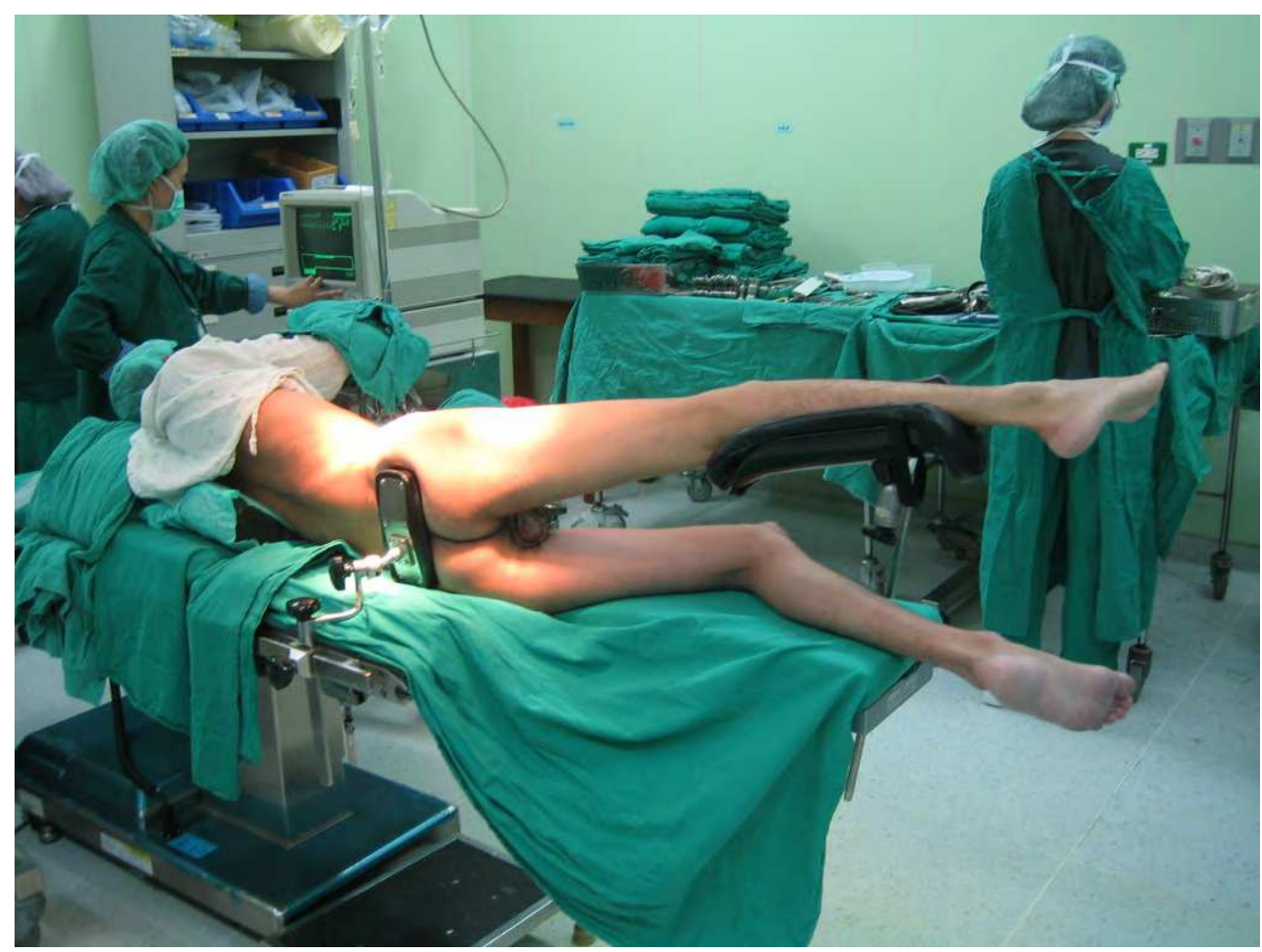

Fig. 4. The special operation table for modified Watson-Jones approach.

Matta et al. has described a unique method of THA using direct anterior approach to the hip. [22] The patient is put on a fracture table that the leg can be pulled by traction in extension and external rotation position. Fluoroscopy can be used during the procedure to control the leg length. However the technique needs a well organized surgical team to adjust the traction and fluoroscopy. Some rare complications such as the ankle fracture or calcaneal fracture have been reported.

\subsection{MIS-THA}

For many years, THA through a reduced wound has been performed in patients on a selective base by many surgeons. However in the past decade, the issue about MIS-THA has provoked great attention and controversy among the society and the publicity. The two-incision technique was publicized by Berger et al. in the Rush-Presbyterian University Hospital. [7,8] In the following years, many studies including prospective randomized trial, large cohort study, case control study, clinical series, and expert opinions about a variety of MIS-THA are reported. As described previously, the MIS-THA can be divided into two categories. The first is the abridged incision MIS-THA and the second is the muscle-sparing MIS-THA.

\subsection{Abridged incision MIS-THA}

Because the major difference between the abridged incision techniques and the conventional techniques is the length of incision, the abridged incision techniques are now more popular 
and acceptable to the orthopaedic surgeons than the muscle-sparing techniques. The abridged incision techniques basically are the modification of the conventional approaches by reducing the skin incision and creating a mobile window for surgical field visualization. Special instruments are designed for the ease of surgery (Figure 5) For the transgluteal approach to the hip joint, about one third to one half of the musculotendinous portion of gluteus medius and minimus are detached from the greater trochanter to facilitate anterior dislocation of the hip joint. Care should be taken not to damage the superior gluteal nerve by overstretching the muscle fibers. For the posterlateral MIS approach to the hip joint, the piriformis tendon or part of the quadratus femoris tendon can be preserved. The hip is dislocated posteriorly by internal rotation, adduction, and flexion. Emphasis has also been on the secure repair of the posterior capsule and the short external rotators after prosthesis implantation. By this modification, this approach proves to be a reliable and safe procedure and the dislocation rates are significantly decreased. [3,4]

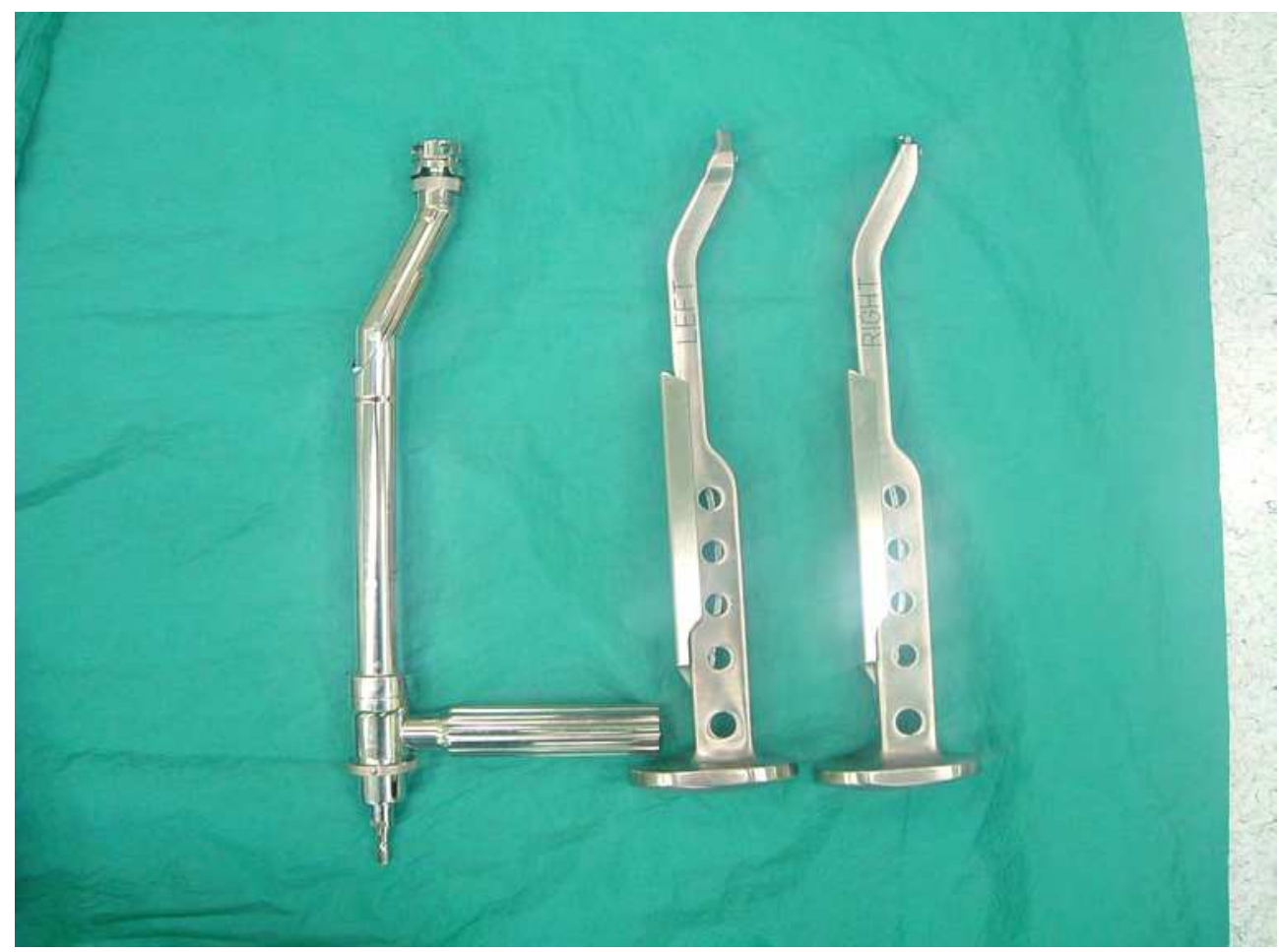

Fig. 5. Dog-legged instruments can be used to avoid skin and soft tissue impingement during MIS surgery.

\subsection{Muscle-sparing MIS-THA}

The muscle-sparing MIS-THA uses tissue intervals and avoids muscle sectioning for prosthesis implantation. Single-incision or multi-incision muscle-sparing MIS techniques have been described in the literatures. The single-incision techniques include the anterolateral (modified Watson-Jones) approach [5] and the direct anterior approach (Smith- 
Peterson) $[6,21,22]$. The multiple-incision techniques include the two-incision approach [711] or the three-incision approach [12]. Although the muscle sparing MIS-THA techniques are also the modification of the classic anterior or anterolateral approach to the hip joint, these techniques are greatly different from the classic ones in terms of the skin incision and tissue dissection. Because the muscles around the hip joint are not cut or detached, dislocation of the hip for the ease of surgical exposure is difficult. Usually a double cut to the femoral neck is needed with one cut over the head-neck junction and the other cut at the desired position above the lesser trochanter.

In MIS direct anterior approach, both acetabular cup and femoral stem can be implanted in a single incision with the patients in the supine position. The single-incision techniques use the Smith-Peterson interval and can be facilitated by using a fracture table or by lowering the leg to hyperextend the hips. [6,21,22]

In the multi-incision techniques, the acetabular cup and femoral stem are separately implanted through different incisions depending on the musculatures and sizes of the patients. Patients can also be placed in supine or lateral position. Intraoperative fluoroscopy is usually advised because direct visualization of the femur during stem implantation is difficult. Under the fluoroscopic guidance, the procedure is very similar to the closed femoral intramedullary nailing technique. [7,8] However by modifying the direction of the skin incisions and position of the patients, the procedure could be done without intraoperative fluoroscopy because direct visualization of the proximal femur is possible. $[1,9,10]$

The muscle-sparing techniques are less popular than the abridged incision or the conventional techniques. The techniques are challenging and need a steeper learning curve because the surgical anatomy and surgical landmarks are less apprehensible among most surgeons and their surgical team members as well. Special instruments, operation table, or additional training are highly demanded to facilitate and to safe-guard the procedures.

\subsection{Clinical results of the MIS-THA}

The increasing popularity of MIS-THA has led to some debates regarding to the safety and clinical results for the "new technologies". Although a decade has been passed, the followup length is still inadequate and good quality randomized control studies are not enough to make a conclusion.

For the evaluation of abridged incision posterior approach, Ogonda had performed a randomized control trial by comparing the standard approach with the MIS-THA approach among different groups of surgeons. Ogonda et al. found the MIS-THA using mini-posterior approach was safe and reliable but provided no extra-benefit as compared to the standard posterior approach in terms of the functional outcomes and the ambulatory ability. [23,24] Kim reported on 60 simultaneous bilateral THA in 30 patients, with each patients serving as his or her own control. [25] The only difference between the MIS-THA and the standard THA was less blood loss in the MIS group. Dorr et al. had combined the imageless navigation system with the mini-posterior MIS-THA technique. They found the MIS-THA using the mini-posterior approach had shortened hospital stays, earlier mobility, less pain, and higher satisfaction in the early postoperative period. [3] The higher satisfaction among the patients with the MIS-THA is associated with the successful implementation of patient education and rehabilitation program. In the high motivated patients, the psychologic expectation and the physical recovery are more realistic. [26] 
The muscle-sparing approaches include the direct anterior, the two- , or the three-incision techniques. Theoretically the muscle sparing techniques should have more rapid functional recovery because the muscles around the hip joint are not violated. As a matter of fact, the muscle sparing techniques are more difficult than the conventional or the abridged incision techniques. Pagnano et al. reported that the muscle-sparing two-incision technique had modest outcomes and substantial complications. [27] By using cadaver studies, they also found evidences of more muscles damage with the two-incision technique than the mini-posterior technique. [28] Others had reported some unusual catastrophic complications and heterotopic ossification by using the muscle-sparing technique. [29,30] As a contrast, high satisfaction and rapid recovery were consistently found in patients treated by experienced surgeons. [7,8,31] Duwelius et al. had compared the two-incision technique with the posterior MIS technique by using historical matchpair control cases and found that the mini-posterior technique had less blood loss and shorter operation time and the two-incision technique had better functional recovery and shorter hospital stays. [31] We had modified the two-incision technique by setting the patient in the lateral position and changed the orientation of the skin incision to facilitate the surgical exposure of the proximal femur. When compared with the standard transgluteal approach, the modified two-incision technique was proven to be safe and had comparable hospital courses and operative results. [1] Using dynamometer to check the muscular torques preoperatively and postoperatively, it was reported that the muscular recovery of the hip flexors were earlier in the postoperative period than the hip extensors by using the modified two-incision technique. [10]

The single-incision muscle-sparing MIS-THA are less reported in the literature except those from the technique developers. [5,6,21,22] Laffosse et al. had compared the anterolateral mini-invasive technique with the posterior mini-invasive approach and reported that both techniques had comparable surgical results and similar implant positioning. [32] Hu et al. had performed a prospective study on 20 patients who had two-incision THA on one hip and modified Watson-Jones THA on the other. [33] It was noted that in the early postoperative period, more patients would prefer the two-incision side to the modified Watson-Jones side. Taking the similarity of the two muscle-sparing techniques in regards to the anterior approach to the hip joint, it was postulated that the manipulation of the leg into hyperextension, external rotation, and adduction in the modified Watson-Jones technique could be the potential reason for the differences in patient's preference. We had used the modified Watson-Jones MIS-THA in more than 400 cases and had perceived similar clinical outcomes as compared with other MIS techniques. However it is usually recommended that special surgical tools, operation table, and a coordinated surgical team are the keys to success. [5,32,33]

\subsection{Navigation \& MIS-THA}

By decreasing the surgical wound, it is difficult to visualize the surgical field in the MISTHA. This surgical exposure is even more limited for the muscle-sparing MIS techniques. Without the help of the visualization of the surgical landmarks during operation, the operation becomes a blind method and is highly dependent on the surgeon's experiences and skillfulness. To safeguard the surgical results and to overcome the difficulty, fluoroscopy is used during the operation to provide real-time image for the verification of the implant positioning. $[7,8,13,14]$ Fluoroscopy can also be combined with the navigation system to verify the size and position of the implants intraoperatively. By implementing the 
computer tomography-based or imageless navigation system with the MIS techniques, the positioning of the acetabular component could be improved by reducing the outliers with more consistent results. [3,34-36] We had adopted an imageless navigation system to the modified two-incision MIS-THA and compared the results with the use of intraoperative fluoroscopy. It was found the imageless navigation system could be a reliable tool for the cup placement as compared to intraoperative fluoroscopy. [9] However the navigation technology for the femoral component implantation is still unsatisfactory. So the navigation system cannot substitute the fluoroscopy for the original combined incision muscle-sparing MIS-THA. As described above, we had modified the two-incision technique by changing the incision direction and the patient positioning. $[1,9,10]$ Similar to the technique described by Irving, the modified technique of two-incision THA can be safely done without the use of fluoroscopy or navigation system. [11] It is noteworthy to emphasize that the use of intraoperative fluoroscopy is not a guarantee to the safety of operation. A hairline fracture which may occur during press-fit of the implant cannot be detected by a fluoroscopy. [19] Such fracture can only be recognized by direct visualization. To overcome this difficulty, a fully porous coated stem is recommended for the muscle-sparing MIS techniques. [7,8,13,14]

\subsection{Safety and complications of MIS-THA}

It is assumed that the complication rates of the MIS-THA would not be lower than the conventional THA and it could be even higher if they were done by inexperienced hands especially by using the muscle-sparing techniques. The enthusiasm for the MIS-THA has declined recently because some complications have alarmed surgeons to practice more cautiously with the new MIS techniques. $[13,27,29,30]$ The MIS-THAs, especially the multiincision muscle-sparing techniques, are considered as unsafe with no proven benefits in clinical recovery or muscle damages. $[27,28]$ The complications associated with the twoincision technique included higher incidence of proximal femoral fractures $(2.8 \%)$ and partial, temporary injures to the lateral femoral cutaneous nerve in the so called "learning curve". [13]

However these reported complications are still not enough to conclude the MIS-THAs, muscle-sparing techniques in particular, are unsafe and associated with more complications. In the literature, the complication rates in conventional posterior or posterior mini-THA were not different with equal rates of infection, dislocation, or peroneal nerve palsy. $[3,25,37,38]$ Ogonda et al. performed a prospectively randomized study on 219 hips by assigning them to conventional posterior or mini-posterior group. [23] The conventional group had 2 mortalities and 1 deep venous thrombosis while the mini-posterior group had 1 infection and 1 dislocation. No mortality were found in the mini-posterior group. In another study comparing conventional and mini-posterior groups, there were even higher complication rates in the conventional group. [39] By reviewing a limited number of patients retrospectively, there were higher rates of complications in the two-incision group as compared with the posterior approach group. [27,31] The two-incision group had higher complication rates (14\% versus 5\%) that included 4 calcar fractures, 1 dislocation, and 2 femoral nerve palsy in the 80 two-incision cases and 4 calcar fractures and 2 dislocations in the 120 posterior cases. [27] In a study of 134 hips in 125 patients by using a modified twoincision technique, there was neither major complications nor perioperative mortality. [40] Linear fractures of the femoral calcar occurred in 6 hips. Transient paresthesia of the lateral femoral cutaneous nerve was seen in 2 patients. 
According to the clinical reports in the literature, the MIS-THA is associated with difficulties in the surgical techniques and should be apprehended by the surgeons to prevent complications.

\subsection{Coordinating the MIS-THA team}

The reasons to use the MIS techniques are to avoid unnecessary tissue destruction, to decrease tissue trauma, to increase patient's satisfaction, and to improve the clinical outcomes. However it is not enough to fulfill the goals for the early recovery by the improvement in the surgical technique alone. The surgical team, the nursing team, the physical therapy team, and the anesthesia team need to be coordinated. The multidisciplinary implementation of clinical pathway, more efficient physical therapy protocols, better anesthesia, effective postoperative pain management, and education programs are equally important as the improvement in the surgical techniques. In the author's institute, the average hospital stay after a THA is about 4 days. When the length of stay shortens, all treatments need to be accelerated without compromising the contents and qualities of medical care. In an interesting study, patients' satisfactions for a MIS-THA were highly related to the psychologic reasons. [26] Those patients who share the decisionmaking processes before choosing the MIS-THA will more likely take responsibility for their outcomes and cope with the treatment team.

For the improvement in the surgical techniques, it is recommended that the surgeon, the assistants, and the nursing staffs should take a training course before start. Because the adoption of a new technology needs a process of learning curve, it is also recommended that the inexperienced surgeons should work with a supervisor for about 20 cases to familiar with all the procedures. The assistants should know their roles and the steps of surgery to streamline the surgical procedures. For the MIS approach, the visualization of the surgical field is difficult for the operating surgeon. It is sometimes impossible for the assistants to see the surgical field. If the assistants can not apprehend their roles and try enthusiastically to see every anatomic detail, the difficulty for the surgeon is increased. The surgical team should use the concept of "mobile window" by moving the retractors back and forth to check the surgical anatomy one at a time. As the treatment team becomes more organized, it is more efficient to provide better quality of care and meet the interest of better patients' satisfaction.

\section{Conclusion}

Although the risks and benefits of MIS-THA are still inconclusive in the literature, nowadays almost all surgeons claim that they adopt some forms of MIS approach into their practice and patient care. [41-47] The reasons include the pressure from the peer groups, the patients' needs, the research and academic interests, the industrial promotion, and the surgeons' self-expectation. Information for the MIS-THA on the internet and other sources impose the MIS-THA as a metaphor of high-tech, quick-recovery, full-function, and bettersatisfaction. As the conventional THA has been developed for more than 50 years and has been one of the most reliable and safe procedure in medicine, we should cautiously adopt the MIS techniques into our practice without any compromising to the gold standards of a successful THA. The fixation, the implant position, the alignment, the choice of the bearing surface, and the recreation of the normal biomechanics are the fundamental parts for long term success. The abridged incision techniques can have smaller wounds but the surgeon 
should not limit the incision length because most the studies indicated there were no difference in the surgical results and the clinical outcomes. For the muscle-sparing techniques, the complications are sometimes catastrophic and unacceptable in inexperienced hands in the learning curve period. The surgeons should take a cautious start by joining expert teams or taking training courses. In conclusion, the concept of MIS-THA has changed the perspectives of patient care in the hip surgery. Increasing awareness of the patients has changed the pattern of orthopedic practice. Orthopedic surgeons should take the full responsibility and master their most familiar and comfortable technique of THA. They should also adopt the MIS-THA into their practice, in the best interests of the patients, to provide long-lasting clinical outcomes and minimize trauma to the patients.

\section{References}

[1] Chen DW, Hu CC, Chang YH, Yang WE, Lee MS. Comparison of clinical outcome in primary total hip arthroplasty by conventional anterolateral transgluteal or 2incision approach. J Arthroplast 2009;24:528-532.

[2] Sculco TP, Jordan LC. The mini-incision approach to total hip arthroplasty. Instr Course Lect 2004;53:141-147.

[3] Dorr LD, Maheshwari AV, Long WT, Wan Z, Sirianni LE. Early pain relief and function after posterior minimally invasive and conventional total hip arthroplasty. A prospective, randomized, blinded study. J Bone Joint Surg Am 2007;89:1153-1160.

[4] Swanson TV. Early results of 1000 consecutive, posterior, single-incision minimally invasive surgery total hip arthroplasties. J Arthroplast 2005;20:Suppl 26-32.

[5] Bertin KC, Röttinger H. Anterolateral mini-incision hip replacement surgery. A modified Watson-Jones approach. Clin Orthop 2004;429:248-255.

[6] Lovell TP. Single-incision direct anterior approach for total hip arthroplasty using a standard operating table. J Arthroplast 2008;23:S64-S68.

[7] Berger RA. Total hip arthroplasty using the minimally invasive two-incision approach. Clin Orthop 2003;417:232-241.

[8] Berger RA, Jacobs JJ, Meneghini RM, Valle CD, Paprosky W, Rosenberg AG. Rapid rehabilitation and recovery with minimally invasive total hip arthroplasty. Clin Orthop 2004;429:239-247.

[9] Lee MS, Kuo CH, Senan V, Chen WJ, Chen LH, Ueng SWN. Two-incision total hip replacement: Intraoperative fluoroscopy versus imageless navigation. Hip International 2006;16 (Suppl): S35-S41.

[10] Chou SW, Ueng SWN, Lee MS. Muscular recovery of hip flexors and extensors after two-incision total hip arthroplasty. Chang Gung Med J 2008;31(6):576-582.

[11] Irving JF. Direct two-incision total hip replacement without fluoroscopy. Orthop Clin N Am 2004;35:173-181.

[12] Kennon RE, Keggi JM, Wetmore RS, Zatorski LE, Huo MH. Keggi KJ. Total hip arthroplasty through a minimally invasive anterior surgical approach. J Bone Joint Surg Am 2003;85(Suppl 4): 39-48.

[13] Archibeck MJ, White RE Jr. Learning curve for the two-incision total hip replacement. Clin Orthop 2004;429:232-238. 
[14] Berry DJ, Berger RA, Callaghan JJ, Dorr LD, Duwelius PJ, Hartzband MA, Lieberman JR, Mears DC. American orthopaedic association symposium: minimally invasive total hip arthroplasty: development, early results, and a critical analysis. J Bone Joint Surg Am 2003;85: 2235-2246.

[15] Solberg BD, Moon CN, Franco DP. Use of a trochanteric flip osteotomy improves outcomes in Pipkin IV fractures. Clin Orthop 2009;467:929-933.

[16] Mardones R, Gonazalez C, Cabanela ME, Trousdale RT, Berry DJ. Extended femoral osteotomy for revision of hip arthroplasty. Results and complications. J Arthroplast 2005;20:79-83.

[17] Hardinge K. The direct lateral approach to the hip. J Bone Joint Surg Br. 1982;64:17-19.

[18] Picado CH, Garcia FL, Marques W, Jr. Damage to the superior gluteal nerve after direct lateral approach to the hip. Clin Orthop 2007;455:209-211.

[19] Hu CC, Yang WE, Chang YH, Chen DWC, Ueng SWN, Lee MS. Fluoroscopy can not recognize intraoperative fracture in patients receiving two-incision total hip arthroplasty. J Arthoplast 2008;23:1031-1036.

[20] Learmonth ID, Allen PE. The omega lateral approach to the hip. J Bone Joint Surg 1996;78-B:559-561.

[21] Bohler N, Hipmair G. The minimal invasive surgery anterior approach with supine patient positioning: a step-wise introduction of technique. Hip International 2006;16(Supp14):48-53.

[22] Matta J, Shahrdar C, Ferfuson T. Single-incision anterior approach for total hip arthroplasty on an orthoaedic table. Clin Orthop 2005;441:115-124.

[23] Ogonda L, Wilson R, Archbold P, Lawlor M, Humphreys P, O'Brien S, Beverland D. A minimal-incision technique in total hip arthroplasty does not improve early postoperative outcomes. A prospective, randomized, controlled trial. J Bone Joint Surg Am 2005;87(4):701-710.

[24] Bennett D, Ogonda L, Elliott D, Humphreys L, Lawlor M, Beverland D. Comparison of immediate postoperative walking ability in patients receiving minimally invasive and standard-incision hip arthroplasty. A prospective blinded study. J Arthoplasty 2007;22:490-495.

[25] Kim YH. Comparison of primary total hip arthroplasties performed with a minimally invasive technique or a standard technique. A prospective and randomized study. J Arthroplasty 2006;21:1092-1098.

[26] Dorr LD, Thomas D, Long WT, Polatin PB, Sirianni LE. Psychologic reasons for patients preferring minimally invasive total hip arthroplasty. Clin Orthop 2007;458:94-100.

[27] Pagnano MW, Leone J, Lewallen DG, Hanssen AD. Two-incision THA had modest outcomes and some substantial complications. Clin Orthop 2005;441:86-90.

[28] Mardones R, Pagnano MW, Nemanich JP, Trousdale RT. Muscle damage after total hip arthroplasty done with the two-incision and mini-posterior techniques. Clin Orthop 2005;441;63-67.

[29] Fehring TK, Mason JB. Catastrophic complications of minimally invasive hip surgery. A series of three cases. J Bone Joint Surg Am 2005;87:711-714. 
[30] Feinblatt JS, Berend KR, Lombardi AV Jr. Severe symptomatic heterotopic ossification and dislocation: a complication after two-incision minimally invasive total hip arthroplasty. J Arthroplasty 2005;20(6):802-806.

[31] Duwelius PJ, Burkhart RL, Hayhurst JO, Moller H, Butler JBV. Comparison of the 2incision and mini-incision posterior total hip arthroplasty technique. A retrospective match-pair control technique. J Arthroplast 2007;22:48-56.

[32] Laffosse JM, Accadbled F, Molinier F, Chiron P, Hocine B, Puget J. Anterolateral miniinvasive versus posterior mini-invasive approach for primary total hip replacement. Comparison of exposure and implant positioning. Arch Orthop Trauma Surg 2008;128(4):363-369.

[33] Hu CC, Chern JS, Hsieh PH, Shih CH, Ueng SWN, Lee MS. Two-incision versus modified Watson-Jones total hip arthroplasty in the same patient - a prospective study on clinical outcomes and patient's preference. Chang Gung Med J 2011 (In Press).

[34] Wixson RL, MacDonald MA. Total hip arthroplasty through a minimal posterior approach using imageless computer-assisted hip navigation. J Arthroplasty 2005;20,Suppl 3:51-56.

[35] Parratte S, Argenson JA. Validation and usefulness of a computer-assisted cuppositioning system in total hip arthroplasty. A prospective, randomized, control study. J Bone Joint Surg Am 2007;89:494-499.

[36] Haaker RGA, Tiedjen K, Ottersbach A, Rubenthaler F, Stockheim M, Stiehl JB. Comparison of conventional versus computer-navigated acetabular component insertion. J Arthroplast 2007;22:151-159.

[37] Geubbels ELPE, Wille JC, Nagelkerke NJD, Vandenbroucke-Grauls CMJE, Grobbee DE, de Boer AS. Hospital-related determinants for surgical-site infection following hip arthroplasty. Infect Control Hosp Epidemiol 2005;26:435-441.

[38] Ridgeway S, Wilson J, Charlet A, Kafatos G, Pearson A, Coello R. Infection of the surgical site after arthroplasty of the hip. J Bone Joint Surg Br 2005;87 (6):844-50.

[39] Khan RJK, Fick D, Khoo P, Yao F, Nivbrant B, Wood D. Less invasive total hip arthroplasty: description of a new technique. J Arthroplast 2006; 21:1038-1046.

[40] Lu ML, Chou SW, Yang WE, Senan V, Hsieh PH, Shih HN, Lee MS. Hospital course and early clinical outcomes of two-incision total hip arthroplasty. Chang Gung Med J 2007;30(6):513-520.

[41] Wright JM, Crockett HC, Delgado S, Lyman S, Madsen M, Sculco TP. Mini-incision for total hip arthroplasty. A prospective, controlled investigation with 5-year followup evaluation. J Arthroplasty 2004;19(5):538-545.

[42] Siguier T, Siguier M, Brumpt B. Mini-incision anterior approach does not increase dislocation rate. A study of 1037 total hip replacements. Clin Orthop 2004;426:164173.

[43] de Beer J, Petruccelli D, Zalzal P, Winemaker MJ. Single incision minimally invasive total hip arthroplasty: length doesn't matter. J Arthroplasty 2004;19(8):945-950.

[44] Howell JR, Masri BA, Duncan CP. Minimally invasive versus standard incision anterolateral hip replacement: a comparative study. Orthop Clin North Am 2004;35(2):153-162. 
[45] Asayama I, Kinsey TL, Mahoney OM. Two-year experience using a limited-incision direct lateral approach in total hip arthroplasty. J Arthroplast 2006;21:1083-1091.

[46] Meneghini RM, Smits SA. Early discharge and recovery with three minimally invasive total hip arthroplasty approaches. Clin Orthop 2009;467:1431-1437.

[47] Labovitch RS, Bozic KJ, Hansen E. An evaluation of information available on the internet regarding minimally invasive hip arthroplasty. J Arthroplast 2006;21:1-5. 


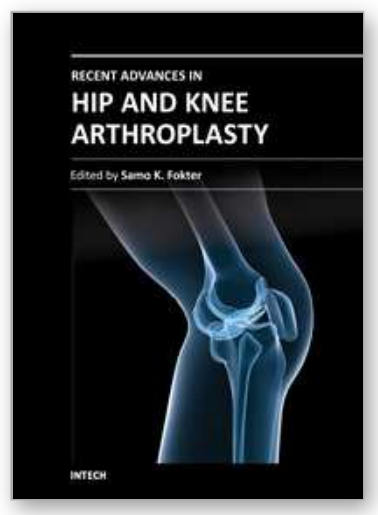

\author{
Recent Advances in Hip and Knee Arthroplasty \\ Edited by Dr. Samo Fokter
}

ISBN 978-953-307-841-0

Hard cover, 452 pages

Publisher InTech

Published online 27, January, 2012

Published in print edition January, 2012

The purpose of this book is to offer an exhaustive overview of the recent insights into the state-of-the-art in most performed arthroplasties of large joints of lower extremities. The treatment options in degenerative joint disease have evolved very quickly. Many surgical procedures are quite different today than they were only five years ago. In an effort to be comprehensive, this book addresses hip arthroplasty with special emphasis on evolving minimally invasive surgical techniques. Some challenging topics in hip arthroplasty are covered in an additional section. Particular attention is given to different designs of knee endoprostheses and soft tissue balance. Special situations in knee arthroplasty are covered in a special section. Recent advances in computer technology created the possibility for the routine use of navigation in knee arthroplasty and this remarkable success is covered in depth as well. Each chapter includes current philosophies, techniques, and an extensive review of the literature.

\title{
How to reference
}

In order to correctly reference this scholarly work, feel free to copy and paste the following:

Mel S. Lee (2012). Minimally Invasive Total Hip Arthroplasty, Recent Advances in Hip and Knee Arthroplasty, Dr. Samo Fokter (Ed.), ISBN: 978-953-307-841-0, InTech, Available from:

http://www.intechopen.com/books/recent-advances-in-hip-and-knee-arthroplasty/minimally-invasive-total-hiparthroplasty

\section{INTECH}

open science | open minds

\section{InTech Europe}

University Campus STeP Ri

Slavka Krautzeka 83/A

51000 Rijeka, Croatia

Phone: +385 (51) 770447

Fax: +385 (51) 686166

www.intechopen.com

\section{InTech China}

Unit 405, Office Block, Hotel Equatorial Shanghai

No.65, Yan An Road (West), Shanghai, 200040, China

中国上海市延安西路65号上海国际贵都大饭店办公楼 405 单元

Phone: +86-21-62489820

Fax: $+86-21-62489821$ 
(C) 2012 The Author(s). Licensee IntechOpen. This is an open access article distributed under the terms of the Creative Commons Attribution 3.0 License, which permits unrestricted use, distribution, and reproduction in any medium, provided the original work is properly cited. 